\title{
A leitura da colonização portuguesa da América no processo de independência do Brasil (1821-1822)
}

Understandings of the Portuguese Colonization of America during the Independence of Brazil (1821-1822)

\section{Cristiane A. Camacho dos Santos}

Mestranda em História

pela Universidade de São Paulo

\section{Resumo}

Este informe de pesquisa apresenta proposições e desdobramentos de investigação de mestrado ainda em curso, sobre a leitura histórica da colonização portuguesa da América no processo de independência do Brasil, cuja pesquisa empírica está baseada na imprensa periódica publicada no Brasil entre 1821 e 1822. Pretende-se identificar, na documentação, as referências a um passado diversificado que é unificado pelo discurso através do adjetivo "colonial" ou expressões semelhantes. Objetiva-se demonstrar que a história da colonização portuguesa da América compreendida como uma trajetória peculiar e específica em relação à história de Portugal é forjada e utilizada como instrumento político para sustentar projetos de futuro que viabilizaram a independência.

\section{Abstract}

This text presents propositions and ramifications of an investigation on the historical understandings of the Portuguese colonization of America during the independence of Brazil; the research focuses on the analysis of the periodic press published in Brazil between 1821 and 1822. I intend to identify how references to a diversified past were unified by expressions such as "colonial" or other similar words. I aim to demonstrate that the history of the Portuguese colonization of America - understood as an special and specific trajectory regarding the history of Portugal - is forged and used as a political instrument in order to support projects of future that made possible the Brazilian independence.

\section{Palavras-chave}

identidade nacional, Independência, Colônia, nação, historiografia

\section{Keywords}

national identity, Independence, Colony, nation, historiography 
NOVAIS, Fernando A. Condições de privacidade na colônia. IN: SOUZA, Laura de Mello e. (org). História da vida privada no Brasil. Cotidiano e vida privada na América portuguesa. São Paulo: Companhia das Letras, 1997. p.13-39; SILVA, Rogério Forastieri da. Colônia e nativismo: a História como "biografia da nação". São Paulo: Hucitec, 1997.

\section{2}

JANCSÓ, István (coord..) Projeto Temático A fundação do Estado e da nação brasileiros (1750 - 1850). São Paulo, $1^{\circ}$ semestre de 2003, p. 8 (mimeo). Sobre essa questão ver WEHLING, Arno. (coord.) Origens do Instituto Histórico e Geográfico Brasileiro. Rio de Janeiro: IHGB, 1989, e WEHLING, Arno. Estado, história, memória. Rio de Janeiro: Nova Fronteira, 1999. Sobre o mesmo tema ver SCHWARCZ, Lilia M., Os guardiões da nossa História Oficial. São Paulo: IDESP, 1995.

3

COSTA, Wilma P. A independência na historiografia brasileira. In: JANCSÓ (org). Independência: História e Historiografia. São Paulo: FAPESP/Hucitec, 2005. p.53-118. Para um panorama correlato sobre a América espanhola ver CHIARAMONTE, Jose Carlos. El mito de las origenes en la historiografia latinoamericana. In: Cuadernos Del Instituto Ravignani, 2. Instituto de Historia Argentina y Americana Dr. Emilio Ravignani, Faculdad de Filosofia y Letras, Universidad de Buenos Aires, s. d. p.1-35, e GUERRA Francois-Xavier. A nação na América espanhola - a questão das origens. Revista Maracanan. Rio de Janeiro: UFRJ, ano 1, nº 1 , 1999-2000.

4

Para a crescente politização das identidades coletivas a partir do último quartel do sécuIo XVIII ver JANCSÓ, István. \&t PIMENTA, João Paulo G. Peças de um mosaico (ou apontamentos para o estudo da emergência da identidade nacional brasileira). In: MOTA, Carlos G. Viagem incompleta - a experiência brasileira. São Paulo: Senac, 2000. p.127-175.

5

Para o acúmulo de experiências associado à condição colonial ver NOVAIS, Fernando A. Op.Cit. A atribuição de um senso de unidade relacionado à colonização era recurso já utilizado desde meados do século XVIII, porém, parte-se da hipótese que tal atribuição se torna qualitativamente diferente no processo de independência do Brasil. Sobre o senso de unidade da América Portuguesa no século XVIII ver KANTOR, Íris. Esquecidos e renascidos. São Paulo - Salvador: Hucitec - Centro de Estudos Baianos/UFBA, 2004. Para a crise do Antigo Regime português na América, ver NOVAIS, Fernando A. Portugal e Brasil na crise do antigo sistema colonial (1777 - 1808). São Paulo: Hucitec, 1995.

\section{Introdução}

As tendências historiográficas mais recentes que discutem a formação do Estado e da nação brasileiros apontam para o problema de se compreender a independência do Brasil como o resultado de uma identidade nacional formada anteriormente, durante a colonização ${ }^{1}$. Formulada no seio da historiografia do século XIX, com o objetivo de conferir uma base de sustentação ao Estado imperial nascente, essa interpretação foi intensamente criticada no século XX2. Tais críticas questionam desde o enraizamento da nação brasileira no passado colonial, passando pelo questionamento da própria ruptura representada pela independência política, até a constatação de que a independência política e a consolidação de sua unidade territorial não foram processos históricos correlatos 3 . Seguindo uma premissa já razoavelmente consensual, podemos afirmar que a correspondência direta entre fundação do Estado e surgimento da nação é um equívoco, uma vez que não há relação imediata entre independência política e sentimento nacional.

Entretanto, a crítica intensa aos "mitos de origem" parece ter ofuscado parcialmente o entendimento dos nexos que conferem inteligibilidade às relações entre fundação do Estado e surgimento da nação, talvez devido à preocupação excessiva em não incorrer nos equívocos para os quais a própria crítica se dirigiu. Se não há uma correspondência imediata entre Estado e nação, é inegável a existência de uma conexão entre esses fenômenos históricos. No bojo do processo de independência do Brasil, em que múltiplos projetos de futuro estavam em questão, surge a preocupação de dar visibilidade e sustentação ao Estado imperial nascente através da transformação das identidades coletivas preexistentes e de suas múltiplas formas de politização; em outras palavras, surge a necessidade de mediar a relação entre Estado e nação ${ }^{4}$. 0 contato com a documentação do período indica para a mesma direção: se não existia uma nacionalidade brasileira em contraposição a uma nacionalidade portuguesa explícita nas lutas políticas que culminaram com a separação entre Brasil e Portugal, não se pode dizer simplesmente que - sobretudo entre 1821 e 1822 - portugueses europeus e americanos não estabeleciam qualquer sentido de diferenciação entre si.

\section{Hipóteses investigativas}

A partir dessa constatação, defende-se a hipótese de que a história da colonização portuguesa da América como uma trajetória peculiar e específica em relação à história de Portugal é forjada e utilizada como instrumento político para sustentar projetos de futuro que viabilizaram a independência. Defende-se, ainda, que a narrativa sobre a experiência colonial, esboçada nos anos de 1821 e 1822, ofereceu subsídios que serão apropriados pela historiografia de meados do século XIX, no sentido de forjar um sentimento identitário baseado numa história peculiar brasileira a partir do passado colonial. Evidentemente, as preocupações aqui apresentadas não têm como objetivo atualizar as explicações formuladas na segunda metade do século XIX, segundo as quais a independência do Brasil seria o resultado de um sentimento nacional crescente; entretanto, tudo indica que o acúmulo de experiências da condição colonial forma também as condições de possibilidade para o surgimento de identidades associadas a um passado específico "brasileiro" que, diferentemente do que ocorrera até então, justificaria projetos de futuro também específicos em meio à crise do Império português e ao processo de independência do Brasil, sobretudo nos anos de 1821 e $1822^{5}$. 
KOSELLECK, Reinhart. Futuro Passado -

Contribuição à semántica dos tempos históricos. Rio de Janeiro: Contraponto, 2006; HARTOG, François. Tempo, história e a escrita da história: a ordem do tempo. In: Revista de História. São Paulo, Departamento de História, Universidade de São Paulo, n.148, p.9-34, 2003.

7

KOSELLECK, Reinhart. Op.Cit.. p.56

8

Ver, por exemplo, Revérbero Constitucional Fluminense, n.VI, 01 de dezembro de 1821 e 0 Conciliador do Reino Unido, 12 de março de 1821.

9

Essa hipótese foi desenvolvida recentemente por ARAUJO, Valdei Lopes de. História dos conceitos: problemas e desafios para uma releitura da modernidade ibérica. In: Almanack Braziliense. (revista eletrônica), n.7, maio de 2008, www.almanack.usp.br

\section{0}

SLEMIAN, Andrea Slemian. Vida politica em tempo de crise. Rio de Janeiro (1808-1824) São Paulo: Hucitec, 2006. p.138. Ver ainda MOREL, Marco. As transformações dos espaços públicos. Imprensa, atores políticos e sociabilidades na Cidade Imperial. (1820-1840). São Paulo: Hucitec, 2005; NEVES, Lucia Maria Bastos Pereira das. Corcundas e constitucionais. A cultura política da independência (1820-1822). Rio de Janeiro: Faperj/Revan, 2003

11

MOREL, Marco. Op.Cit.

12

lbidem

13

JANCSÓ, István. \& PIMENTA, João Paulo G. Peças de um mosaico (ou apontamentos para o estudo da emergência da identidade nacional brasileira). In: MOTA, Carlos G. Viagem incompleta - a experiência brasileira. São Paulo: Senac, 2000
Essas hipóteses parecem significativas tendo em vista a gradual ruptura anunciada no mundo ocidental de meados do século XVIII, com a transformação na concepção político-filosófica da historia magistra vitae6. Com a tendencial perda da operacionalidade de tal concepção, anuncia-se uma nova, de um tempo histórico que remete à unicidade dos fatos e que confere à história um caráter processual. Esse é, segundo Koselleck o principal traço distintivo da modernidade que implica no reconhecimento de um tempo inédito e, por esse motivo, o passado deixaria de ter funções normativas para o presente? Tal caráter, que ganhava força no mundo ocidental no final do século XVIII, implicava aos homens da época um futuro incerto, impossivel de prever e, por isso, objeto de controle.

A percepção da aceleração do tempo histórico e a tentativa de controle de um futuro em fuga, concebidas por Koselleck, se manifestam com freqüência na documentação utilizada nesta pesquisa. ${ }^{8}$. Isso não significa, contudo, que os exemplos históricos não fossem mais acionados. Observa-se, pelo contrário, a coexistência da história processual com um sentido providencialista da História, assim como com a história exemplar. A convivência do topos da historia magistra vitae com uma nova concepção histórica, processual, que não permite a previsibilidade e a repetição dos fatos, poderia tornar-se, assim, um elemento problematizador e relativizador do pressuposto koselleckiano. Poderia levar, portanto, ao questionamento da operacionalidade desse referencial teórico. Entretanto, defende-se que, a recorrência da mobilização dos exemplos históricos traz consigo a erosão da história como mestra e a preocupação com o controle do "futuro em fuga", diante da conjuntura histórica de crise. Dessa forma, muito mais do que uma certa resistência ao moderno sugerida pela permanência de parâmetros clássicos do conceito de história, parece que a história exemplar estava sendo, progressivamente, adaptada ao conceito moderno de história9.

\section{Imprensa periódica - fonte e tema de pesquisa}

A imprensa periódica assume, no contexto de politização das identidades coletivas, um papel privilegiado para análise porque intensifica o debate sobre os interesses públicos em Portugal e no Brasil. 0 estabelecimento da liberdade de imprensa no Brasil, em março de 1821, provoca a proliferação na circulação de panfletos e periódicos que, por sua vez, fornecem "materialidade para um debate político, anteriormente muito incipiente, visivelmente incrementado pelas transformações vividas no periodo, em especial o crescente interesse pelas questões de governo"10. Os periódicos transformam-se, ao mesmo tempo, em expressão e condicionante da constituição de um espaço público de discussão no mundo luso-americano ${ }^{11}$.

Os periódicos se tornariam, também, verdadeiras armas de luta política em defesa de interesses que, mesmo que divergentes, atribuem ao Brasil um papel de destaque no Império português. Identificar a recorrência da mobilização de argumentos históricos para a afirmação do Brasil como entidade política, a despeito das divergências políticas entre os periódicos, é fundamental para esta investigação porque se pretende analisar as fontes não apenas como reduzidas simplesmente a "máscaras" de interesses econômicos ${ }^{12}$, mas principalmente tendo em vista o quadro de reordenamento de múltiplas identidades políticas no contexto de crise e superação do Antigo Regime português ${ }^{13}$. Seguindo a assertiva de Benedict Anderson, a imprensa periódica representa o recurso técnico para o reordenamento e criação de identidades políticas. Em outras palavras, a arbitrariedade da 
ANDERSON, Benedict. Nação e consciência nacional. São Paulo: Ática, 1989.

O Amigo do Rei e da Nação, 1821, s/d.

inclusão e justaposição de informações coincidentes no calendário, assim como a reiteração de recursos discursivos em comum, possibilitariam o enraizamento de um mundo imaginado na vida cotidiana, permitindo a produção de consciência de pertencimento político ${ }^{14}$.

\section{Desdobramentos de pesquisa}

Até o momento, procedeu-se ao levantamento e consulta da documentação periódica publicada no Rio de Janeiro em 1821, o que permitiu a identificação de elementos comuns no que diz respeito à instrumentalização do passado, a despeito das divergências políticas entre os periódicos analisados.

Os primeiros periódicos a circular no Rio de Janeiro após a instauração da liberdade de imprensa, em março de 1821, exaltam a decisão do rei ao jurar as bases da Constituição portuguesa. Glorificam os efeitos provocados no Brasil por essa decisão, geralmente, declarando fidelidade à monarquia portuguesa e à dinastia de Bragança. É o que observamos nos periódicos monarquistas 0 Amigo do Rei e da Nação, de Ovídio Saraiva de Carvalho e Silva, e 0 Conciliador do Reino Unido, de José da Silva Lisboa. Eram jornais publicados por pessoas que ocupavam cargos públicos ou que estavam ligados a pessoas que os ocupavam, e defendiam a continuidade da união luso-americana e a permanência de D. João no Brasil. Em março de 1821, o Amigo do Rei e da Nação publica carta de correspondente que exalta o juramento de D. João às bases da constituição, em 26 de fevereiro, realizando uma narrativa de louvor ao Brasil desde a chegada dos portugueses:

Se o Brasil enriquecido em seu princípio com os dons da natureza, juntou a eles os bens da sociedade, quando em 1500 fez parte da Lusa monarquia; se em 1808, a salvo da tormenta que ameaçava Portugal e quase a Europa inteira, acolheu dentro em seu seio o Atual Imperante e o viu nas praias do Janeiro empunhar o cetro que a Nação impaciente de sofrer estranho jugo, valerosa arrancou a destra do monarca espanhol, que lho extorquira e dele fez espontânea entrega à Casa augusta de Bragança em 1640; se o Brasil levantado à Dignidade de reino, tinha por longa série de sucessos um nome respeitável, agora mais do que nunca o verá eternizado. 0 portentoso dia 26 de Fevereiro de 1821 abrilhantou seus Fastos e neles marcou Época de sua maior glória ${ }^{15}$.

0 discurso é organizado através de uma perspectiva histórica que atribui à colonização portuguesa da América um caráter civilizatório, recurso que será recorrente nos demais periódicos de 1821. A transferência da Corte, seguida da elevação do Brasil à condição de reino, tem seu desfecho glorioso pelo juramento de D. João às bases da Constituição. A exaltação da dinastia de Bragança e, por conseguinte, da monarquia portuguesa, também é caracterizada a partir de referenciais históricos, como a restauração, e tem sua trajetória estreitamente ligada ao Brasil, havendo uma coincidência histórica entre a monarquia portuguesa e sua porção americana através da transferência da Corte para o Novo Mundo. Contudo, o discurso estrutura-se tendo em vista um substantivo, o Brasil, que agora tem sua glória "eternizada" pelo juramento das bases da constituição. Não se trata, somente, de simples louvor à dinastia de Bragança - o que demonstraria a posição monarquista do discurso - mas sim de enfatizar a nova dignidade histórica do Brasil intimamente relacionada com a história da monarquia portuguesa. O Amigo do Rei e da Nação esforçava-se para demonstrar que a prosperidade do Brasil estava atrelada (inclusive histo- 


\section{6}

Revérbero Constitucional Fluminense, n.I, 15 de setembro de 1821.

17

Revérbero Constitucional Fluminense, n.III, 15 de outubro de 1821

18

Além da Justa retribuição dada ao compadre de Lisboa em desagravo aos brasileiros ofendidos por várias asserções que escreveu na sua carta em resposta ao compadre de Belém pelo filho do compadre do Rio de Janeiro que a oferece e dedica aos seus patricios, somamse a ela o Discurso que em desagravo aos Brasileiros ofendidos pelo Compadre de Lisboa na sua Carta impolitica dirigida ao Compadre de Belém; a Carta que em defesa dos brasileiros insultados escreve ao sacristão de Carahi o Estudante Constitucional, amigo do filho do compadre do Rio de Janeiro; a Carta do compadre do Rio São Francisco ao filho do compadre do Rio de Janeiro e, por fim, a Resposta analytica a hum artigo do Portuguez Constitucional em defeza dos direitos do Reino do Brasil, por hum fluminense ricamente) à monarquia portuguesa e à dinastia de Bragança. Por isso, a conservação de sua integridade e glória continuaria (ou deveria continuar) atrelada às decisões reais. E mais: a estratégia de coincidência histórica entre o Brasil e a dinastia de Bragança parece corroborar a manutenção da família real no Brasil, uma vez que sua prosperidade fora intimamente atrelada ao evento da transferência.

Em oposição ao gênero laudatório e vinculado ao poder oficial do Estado, o Revérbero Constitucional Fluminense, já em seu primeiro número, louva os ideais da revolução do Porto, aderindo ao sistema constitucional. Segundo os redatores:

Foi belo e majestoso o espetáculo da Liberdade plantando o seu estandarte no Brasil, que rojava há três séculos os vergonhosos ferros da escravidão. ${ }^{16}$

Observa-se o esforço de inscrever Portugal e Brasil num mesmo processo histórico, à semelhança do que já fizera os periódicos que circulavam no Rio de Janeiro desde o primeiro semestre de 1821. A referência ao passado de opressão, mesmo que portadora de algo potencialmente novo e transformador, está esvaziada de conteúdo específico; pelo contrário, o passado superado que afligia "portugueses de ambos os hemisférios" é a "opressão" e o "despotismo", argumento também recorrente na documentação até agora analisada. 0 processo de colonização portuguesa da América, pelo contrário, é referido positivamente, como elemento de prosperidade e capacidade civilizacional. Em 15 de outubro de 1821, por exemplo, o periódico reforça os laços de união através de uma narrativa da colonização na qual a argumentação principal gira em torno dos enlaces entre Brasil e Portugal desenvolvidos ao longo da história da colonização e coroados pelo triunfo do sistema constitucional17. 0 mesmo se observa em narrativas presentes em outros periódicos do primeiro semestre de 1821.

A despeito de divergências políticas entre os periódicos, observamos elementos comuns no que diz respeito às leituras do passado. Portugal e Brasil são apresentados, indistintamente, como vitimas do despotismo. A ruptura representada pela revolução constitucionalista teria efeitos semeIhantes para os dois reinos e reforçaria os laços de união entre eles. Somase a isso, o louvor dedicado à colonização portuguesa da América como elemento que teria trazido ao Brasil prosperidade e civilização. Já em 1821, manifesta-se, também, a politização do Brasil atrelada à sua elevação à condição de reino, elemento que canalizaria, em 1822, as reivindicações por reciprocidade recorrentes no discurso. Dessa forma, observamos uma operação discursiva comum e recorrente em 1821, que procura superar um passado de despotismo, porém ainda genérico e pouco qualificado, em nome de virtudes e princípios lusitanos dos quais os luso-americanos seriam (ou reconheciam-se como) herdeiros. Entretanto, freqüentemente, os discursos estabelecem distinção entre portugueses europeus e americanos.

A reivindicação de reciprocidade entre os dois reinos orienta o olhar para o passado e, num momento de reordenamento político do Império português, torna-se potencializadora de incompatibilidades entre Brasil e Portugal. É o que indica um conjunto de cinco panfletos, todos publicados entre setembro e dezembro de 1821 no Rio de Janeiro ${ }^{18}$. 0 mais conhecido deles é a "Justa retribuição dada ao Compadre de Lisboa", cuja autoria é atribuída a Luis Gonçalves dos Santos. Ela é uma resposta a um artigo escrito para o jornal português Astro da Lusitânia, de um tal "Compadre 
19

Justa retribuição dada ao compadre de Lisboa em desagravo aos brasileiros ofendidos por várias asserções que escreveu na sua carta em resposta ao compadre de Belém pelo filho do compadre do Rio de Janeiro que a oferece e dedica aos seus patrícios. Rio de Janeiro: Imp. Nacional, 1822.

20

Ibidem. de Lisboa", que defendia a preponderância dos interesses de Portugal em detrimento do reino do Brasil. Circulou em setembro de 1821 e, em segunda edição, em fevereiro de 1822. Seu conteúdo é uma defesa da dignidade do reino do Brasil, apresentando algumas interpretações acerca do passado colonial. Em resposta à afirmação do "Compadre de Lisboa" sobre se Portugal se tornaria "colônia" do Brasil com a permanência da família real no Rio de Janeiro, argumenta que Portugal não foi destituído, com a transferência da Corte, de suas leis, forais, prerrogativas e instituições,

coisas que nunca houveram [sic] no Brasil antes da vinda de S. Majestade. E infelizmente nem era contemplado nos Títulos inerentes à Coroa, não tinha Escudo de Armas [e] não podia comprar nem vender senão aos negociantes do Porto e de Lisboa: os seus Portos estavam cerrados a todos os Estrangeiros, não the eram permitidas fábricas, nem indústria de qualidade alguma; nunca teve, nem ainda tem, uma Universidade, que não seja exclusivamente a de Coimbra; os Vice-Reis e Governadores eram mandados de Portugal, e os mesmos Bispos quase todos eram Europeus; [...] nunca foi permitido ao Brasil agricultar outras produções, que não fossem as propriamente chamadas coloniais ${ }^{19}$.

A conclusão denuncia claramente o caráter exploratório da colonização portuguesa:

Diga-me agora, Senhor Compadre; com a estada de Sua Majestade no Brasil Portugal chegou, ou recearia chegar a esses apertos, a esta degradação, que constitui o verdadeiro estado de Colônia, de que v.m. tanto se horroriza? [...] Nós os Brasileiros, a pesar de sermos colonistas [sic] ou perto de três Séculos, sofremos com paciência a nossa sorte; fomos sempre submissos, e fiéis ao nosso Soberano, nunca levantamos a voz ${ }^{20}$.

Se nos discursos anteriormente apresentados, predomina a instrumentalização do passado para reforçar a unidade da monarquia portuguesa e a prosperidade do Brasil, agora a colonização portuguesa da América é compreendida como sinônimo de exploração e opressão específica e historicamente qualificadas. A utilização do vocábulo "brasileiro" torna-se, também, cada vez mais freqüente. Essa mudança qualitativa ganha força em janeiro de 1822, a partir da decisão de D. Pedro em permanecer no Brasil, desobedecendo às ordens das Cortes. No folheto de 1821, associamse ao discurso histórico elogios ao clima, vegetação, dimensões territoriais, riqueza e diversidade natural do Brasil, caracteristicas que justificariam a reciprocidade entre os dois reinos. Isso não significa que o panfleto defenda a independência, pelo contrário, exalta a monarquia e a dinastia de Bragança como elementos de união entre eles. Convém notar, entretanto, que não se trata da simples união dos portugueses de todos os lugares, mas sim de afirmação da união de partes distintas e definidas, momento em que o Brasil parece ganhar materialidade como entidade política.

0 folheto não abandona, ainda, a idéia de que há um elemento civilizatório no empreendimento colonial. Em reação à acusação do Compadre de que o Brasil seria habitado apenas por "hordas de negrinhos" trazidos da costa da África, Luis Gonçalves dos Santos argumenta que no Brasil existiam índios "bravos" e cristianizados, além de "pardos" e "pretos" nascidos no pais e:

encontram-se também muitíssimos brancos sem outra mescla de sangue, que não seja todo Português, ou nascidos na Europa ou no Brasil: foram estes os que edificaram as nossas Cidades, os que as povoaram; os que levantaram estas fortalezas e as defendem; os que formaram sempre a parte mais distinta e respeitável dos 
21

Justa retribuição dada ao compadre de Lisboa em desagravo aos brasileiros ofendidos por várias asserções que escreveu na sua carta em resposta ao compadre de Belém pelo filho do compadre do Rio de Janeiro que a oferece e dedica aos seus patrícios. Rio de Janeiro: Imp. Nacional, 1822.

\section{2}

BERBEL, Marcia Regina. A retórica da recolonização. In: JANCSÓ, István (org). Independência: história e historiografia. São Paulo: Hucitec, 2005. p.791-808.; BARMAN, Roderick. Brazil: the forging of a nation. 1798 - 1852. Califórnia: Stanford University Press, 1988.; ROCHA,

Antônio Penalves. A economia política na desagregação do Império português. In: CARDOSO, José Luis. A economia política e os dilemas do império luso-brasileiro (1790-1822). Lisboa:

Comissão Nacional para as comemorações dos descobrimentos portugueses, 2001. p.149-197.

23

ZERMEÑO PADILLA, Guillermo. História, experiência e modernidade na América ibérica. Almanack braziliense (revista eletrônica), n.7, maio de 2008, www.almanack.usp.br

\section{4}

Para as determinações reciprocas entre os processos de independência nas Américas portuguesa e espanhola ver PIMENTA, João Paulo G. 0 Brasil e a América Espanhola (18081822). 2003 (tese de doutorado). Faculdade de Filosofia, Letras e Ciências Humanas da USP, São Paulo, 2003. Para a importância da transferência da Corte e da escravidão na politização de uma identidade especifica do Brasil ver JANCSÓ István. \& PIMENTA, João Paulo G. Peças de um mosaico lou apontamentos para o estudo da emergência da identidade nacional brasileira). In: MOTA, Carlos G. Viagem incompleta - a experiência brasileira. São Paulo: Senac, 2000.
Cidadãos; os que compõem o corpo do Clero Secular e Regular, os que exercem a Magistratura, e os demais empregos públicos; os que estabeleceram as Casas de Comércio, e as conservam; os que são Proprietários, Senhores de Engenhos, ou de lavras minerais: Fazendeiros, Mercadores, Artistas, Mestres de Ofícios mecânicos [...]; são finalmente os brancos, os que em geral compõem a Tropa tanto da primeira, como da segunda linha, e especialmente a sua briosa, valente e distinta Oficialidade. $^{21}$

Manifesta-se, aqui, a ambigüidade que atribui à colonização portuguesa um caráter ao mesmo tempo exploratório e civilizacional que parece tornar operacional uma distinção entre "colonos" ou "ex-colonos" e "metropolitanos" ou "recolonizadores", operação discursiva levada a cabo a partir de dezembro de 1821, em torno da movimentação em defesa da permanência de D. Pedro no Brasil22. Se da perspectiva historiográfica, a relação entre colônia e metrópole não se coaduna mais com a realidade desde 1808 , o reconhecimento de uma ancestralidade colonial presente na documentação, parece transformar tal relação em arma de luta política disponível e amplamente utilizada na dinâmica da independência.

A fórmula "trezentos anos de opressão", já recorrente nos discursos durante as guerras de independência hispano-americanas, ${ }^{23}$ é defendida com freqüência e amplamente evocada no mundo luso-americano. Ela reconfigura a experiência acumulada de vários séculos, criando condições para a projeção de uma história do Brasil peculiar em relação a de Portugal como signo de distinção entre duas partes a serem mantidas em união, mas portando uma carga de subversão dessa relação, com a qualificação dessa experiência como negativa; assim como, uma experiência a ser superada. Por outro lado, os "trezentos anos" da presença portuguesa na América também se apresentam como referência positiva, capaz de conferir unidade à monarquia portuguesa, assim como coesão e civilização ao Brasil. Elementos como o reconhecimento de unidade histórica entre os destinos da América portuguesa e da América espanhola, a conjuntura histórica decorrente da transferência da Corte para o Rio de Janeiro e, por fim, a posição do Brasil como um dos esteios da escravidão na América são, indiscutivelmente, determinantes de tal ambigüidade e devem ser sopesados nesta investigação 24 .

Conforme procuramos indicar brevemente, o discurso histórico, e, em especial, a leitura da colonização portuguesa da América, parece ter dado materialidade à singularização da história do Brasil num momento crucial de reordenamento político, criando condições para projeções de futuro que, em 1822, tornar-se-iam incompatíveis com a indivisibilidade da nação portuguesa tal como preconizada pelas Cortes lisboetas e que, progressivamente, viabilizariam a independência política do Brasil.

\section{Desenvolvimento da investigação}

Como ações futuras de pesquisa, pretende-se proceder ao levantamento e à leitura dos periódicos publicados no Rio de Janeiro em 1822 e daqueles publicados nas províncias da Bahia, Pernambuco, Pará e Maranhão, em 1821 e 1822. Através de mapeamento prévio, observa-se a crescente utilização, em 1822, de expressões como: "três séculos de opressão", "estado de colônia", "ferros do antigo despotismo", "sistema de colonização", "passada educação colonial", "recolonização" e "antiga escravidão colonial", que deixam subjacente um caráter valorativo negativo na apropriação de um passado específico e parecem dar força à singularização da história do 
25

A compreensão do modelo de colonização aos quais os discursos politicos fazem referência é questão de extrema relevância. Parece-nos haver uma classificação implícita nos discursos entre colonização antiga e colonização moderna que atribui ao primeiro modelo um caráter positivo, civilizacional e, ao segundo, um caráter negativo, sinônimo de despotismo. Entretanto, conclusões a esse respeito necessitam de maiores esforços investigativos.

\section{6}

KOSELLECK, Reinhart. Futuro Passado -

Contribuição à semántica dos tempos históricos. Rio de Janeiro: Contraponto, 2006. p.312.

\section{7}

PIMENTA, João Paulo G. De Raynal a De Pradt: apontamentos para o estudo da idéia de emancipação da América e sua leitura no Brasil (1808-1822). Comunicação apresentada no Seminário Internacional Brasil: de um império a outro (1750-1850). São Paulo, Universidade de São Paulo, setembro de 2005.

\section{8}

Revérbero Constitucional Fluminense, n.IV, $01 / 11 / 1821$.

\section{9}

ZERMEÑO PADILLA, Guillermo. História, experiência e modernidade na América ibérica. Almanack braziliense (revista eletrônica), n.7, maio de 2008, www.almanack.usp.br
Brasil. Torna-se cada vez mais recorrente a rubrica de "colonial" ao período anterior a 180825. Observa-se que, na medida em que se consolida um projeto de manutenção do reino do Brasil e dos interesses políticos em torno da regência de $\mathrm{D}$. Pedro, ocorre a resignificação de experiências já adquiridas, uma vez que novas experiências abrem expectativas diferentes ${ }^{26}$. Por conseguinte, a dinâmica política modifica constantemente a leitura do passado colonial que adquire conteúdos novos e inovadores.

As denúncias do caráter exploratório da colonização moderna e o anúncio da inevitabilidade da emancipação política da América são abundantes em 1822, em especial, as apropriações de leituras de Raynal e De Pradt, autores cujas idéias já eram disponiveis e amplamente divulgadas nos espaços públicos de discussão do período 27 . Tais reflexões manifestam-se, no Revérbero Constitucional Fluminense desde $1^{\circ}$ de novembro de 1821. Mesmo quando afirmam a "cordial aliança" que reúne Brasil e Portugal "há três séculos em corpo de monarquia", os redatores advertem que não convém ao Brasil "um governo de tutela porque é da natureza de um tal governo que os subordinados a ele procurem livrar-se da sujeição do tutor"28. Dessa forma, as referências ao caráter exploratório da colonização moderna e sobre a inevitabilidade da emancipação política da América em associação com a citação ou apropriação de autores franceses como Raynal e De Pradt devem ser observadas com atenção.

A fórmula "três séculos de opressão", crescentemente evocada em 1822, sugere uma nova relação com o tempo que condensa o espaço de experiência (três séculos) oposto ao presente cujo desenlace é desconhecido, e que, por isso necessita de prognóstico. Nesse sentido, não se perde de vista a importância da mobilização do "passado recente", reconhecidamente específico do Brasil, para instrumentalização de projetos igualmente específicos 29 .

Conforme procuramos indicar, a leitura histórica da colonização portuguesa da América durante o processo de independência é uma das dimensões da transformação das identidades coletivas e de seu processo de politização e, por isso, deve conduzir ao esclarecimento de algumas mediações entre Estado e nação pouco conhecidas. 